\title{
Investigating the Applicability of Multiple Intelligence Theory in Pilot Assessment and Training
}

\author{
Edward J. Overchuk \\ Kent State University \\ Mary Niemczyk \\ Arizona State University
}

\begin{abstract}
This investigative paper and research explores the Theory of Multiple Intelligence (MI) as defined by Gardner (1983, 1999) and its applicability in the assessment and education of commercial pilots. Multiple intelligence theory proposes that individuals have eight distinct intelligences with strengths in one or more of the intellects. The authors suggest that MI theory is more useful in describing cognitive processes in aviators than singular (IQ score) or general intellect theories. Beyond just describing cognitions, MI theory could be used to improve pilot training by expanding on educational methods suggested by the Federal Aviation Administration (FAA). Currently, most instructional methods for pilots are traditional in nature, which utilize lectures, cognitive-behavioral techniques, and one-on-one tutorial lessons. MI theory has rarely been applied to the design of aviation education (Craig \& Garcia, 2001). To determine a pilot's intelligence profile, the Multiple Intelligence Developmental Assessment Scale (MIDAS) was utilized in this investigation. From a sample of 31 professional aviators and 55 college flight students a common MI profile became evident. A descriptive analysis of the MIDAS scores indicated that both professional pilots and flight students scored high on Intrapersonal and Spatial Intelligence. The "pilot profile" found in this investigation replicates past research in the development of the MIDAS. Because most pilots in this study have similar profiles, educational programs could capitalize on these intellectual strengths. Furthermore, if a flight student scores low on important intellectual strengths for flight, instructional and learning strategies could be implemented to match the student's intellectual strengths.
\end{abstract}

\section{INTRODUCTION}

What does it mean to be intelligent or how is one person more intelligent than another? "Because intelligence is assessed by members of a society, its conceptualization often takes several forms that can vary according to when, where, and how the assessment occurs" (Davidson \& Downing, 2000, p. 34). Aviation has its own conceptualizations of pilot intelligence, which are often reflected in the various testing practices and evaluations that most pilots go through. The first battery of mental tests can be traced back to Sir Francis Galton during the late 1800s (Gregory, 2004; Kaufam \& Lichtenberger, 1999). Galton studied gifted individuals and he believed that since people take in information through their senses the most intellectual person would have the greatest perceptual ability (Kaufam \& Lichtenberger, 1999). The actual term "mental test" was not conceived until Cattell published his research in 1890 (cited in Gregory, 2004).
Much of Cattell's work relied on Galtonian concepts. However, he incorporated some added features including the strength of a person's handshake, hypothetically indicating an individual's mental power. Surprisingly, these early mental tests were not scientifically scrutinized until 30 years later. Eventually, researchers tried to predict academic performance through the testing of sensory discrimination and reaction times (Wissler, 1901). Being unable to find positive correlation between test scores and academic achievement, Galtonian theories began to lose their appeal.

Early in the 1900's, Alfred Binet was asked by the French government to find a way to determine which students would not benefit from regular instruction (Armstrong, 2000; Gregory, 2004). Binet's assessment marked the first formal scale for measuring intelligence in children and was the beginning of modern intelligence testing (Gregory, 2004). In 1916, Terman and associates began revising the Binet- 
Simon Intelligence Scales to produce the Stanford-Binet intelligence test and the resultant IQ (Intelligence Quotient) score. This swept through American intelligence testing and became one of the most popular and debatable subjects in psychology. The singular concept of IQ, or "g", would be "etched" into intelligence testing for decades (Shearer, 2004a).

There are many ways to define intelligence (Wolman, 1985) and conceptually, intelligence can be whatever the mental test is attempting to measure (Boring, 1923). Many intelligence models that describe intellect through the lens of cognitive and physiological components are often identified as "IQ" (Davidson \& Downing, 2000; Kaufam \& Lichtenberger, 1999; The Psychological Corporation, 1997). Dissatisfied with the unitary view of intelligence (IQ), Howard Gardner proposed the theory of multiple intelligence (Gardner, 1983, 1993). Gardner (1999) defines intelligence as, “a biopsychological potential to process information that can be activated in a cultural setting to solve problems or create products that are of value in a culture” (p. 34).

Gardner's definition of intelligence incorporates easily into aeronautical terms (Overchuk, 2008a, 2008b, 2008c). "Pilots are part of a unique culture (commercial aviation and aviation as whole) and they must continually process information to solve novel problems. A pilot must also deliver a service (product) that is reliable, yet maintain a balance between safe operations and reliability. These pilot potentials are highly valued by society and the flying public" (Overchuk, 2008a, p. 10).

Gardner initially suggested the existence of seven intelligences (Gardner, 1983). In 1999, he increased the number to eight distinct intelligences: Linguistic, Logical-mathematical, Spatial, Kinesthetic, Musical, Naturalist, Interpersonal and Intrapersonal (Gardner, 1999).

Linguistic intelligence is the "intellect of words" (Armstrong, 1999). People with this type of intelligence tend to be lawyers, editors, journalists, and educators (Armstrong, 2000; Shearer, 2004b). Logical-mathematical intelligence is the ability to use numbers successfully, reason well, and to have strong problem solving skills (Armstrong, 2000). This form of intelligence is found in scientists, pilots, accountants, and philosophers (Armstrong, 1999). Spatial intelligence is the ability to think in pictures and images. Individuals with this intelligence can transform and recreate different aspects of the visual-spatial world through mental imagery. Professions requiring strong spatial skills include aviation, architecture, and mechanical engineering.

Body-Kinesthetic intelligence is an expertise in using one's whole body to express feelings, ideas, and to manipulate objects in goal directed behaviors (Armstrong, 2000; Shearer, 2004b). Surgeons, karate masters, athletes, and mechanics usually possess strong bodykinesthetic intelligence. Musical intelligence is the ability to perceive, appreciate, and produce different types of melodies. Individuals strong in this intelligence are sensitive to pitch, timber, and tone (Armstrong, 1999). People possessing strengths in this area compose music and tend to be music teachers (Lazear, 1991).

Interpersonal intelligence is the ability to detect the moods, feelings, intentions and to understand other people (Armstrong, 1999). Individuals with interpersonal intelligence tend to be successful educators, counselors, and psychologists. Intrapersonal intelligence is the capacity to think about thinking. Essential functions of this intelligence include goalsetting, self-appraisal, self-monitoring/correction and emotional self-management (Shearer, 2004b). Introspection and self-regulation are key features of this intellect. A person with a strong intrapersonal intelligence can be successful in most endeavors including careers in aviation, education, law enforcement and theology (Shearer, 2007). The final intelligence is the Naturalist. This intellect gives one the ability to empathize, recognize, and understand natural things (plants, animals, and biology). Naturalists have a sensitivity toward natural phenomenon, such as cloud formations and weather patterns (Armstrong, 2000).

People can have strengths in one or more of the eight intelligences and the intellects interact uniquely for each individual (Armstrong, 2000). Gardner suggests that it is better to describe intellect as those independent and interacting intellectual capacities (eight intelligences), because it will be more useful to educators than an enormous collection of sensory-perceptual 
modules or a single “all-purpose” intelligence (Gardner, 2006; Gardner \& Moran, 2006). For example, sensory-perceptual and information processing theories explain human learning through a variety of models. These models emphasize that the human brain can be conceptualized as a computer (Anderson, 1995; Federal Aviation Administration, 2008). To the author's, these theories make important contributions to the science of learning. In general, these models stress the interplay of the sensory register, short-term memory, and longterm memory. Deep learning does not occur until information is successfully transferred to long-term memory. The use of Multiple Intelligence theory with related instructional and learning strategies may enhance this transfer. The theory of Multiple Intelligence validates what many educators' experience in the classroom (Chen, 2004; Kornhaber, 2004; Ucak, Bag, \& Usak, 2006). Simply put, students learn and think in many different ways and complicated sensory perceptual models or allpurpose intelligence scores may not provide the instructor with enough information about the diverse learning requirements of his/her students. MI theory seems very applicable to flight education because the MI profile can be used as a template to develop lectures, enhance flight instruction strategies and possibly develop teaching/learning strategies based on the instructor's and the student's multiple intelligences (Overchuk, 2008c, 2009). The cognitive sciences do a great job of capturing some features of learning, unfortunately they are "decontextualized" from the process of flight education (Lintern, 1995).

As flight educators and commercial aviation personnel, it seems evident that pilots must utilize more intellectual domains than the culturally valued linguistic and logicalmathematical intelligences. Beyond having excellent flying skills, the pilot must have Interpersonal Intelligence so he/she can work with a multitude of people including, crewmembers, passengers, gate-agents, FAA Inspectors, air traffic controllers and dispatchers, among others. In order for these human interactions to operate smoothly, the pilot must tap into their interpersonal intelligence.
Pilots also need strong Intrapersonal Intelligence because they must self-monitor and self-regulate to stay within FAA regulations, stay vigilant, and to fulfill society's high expectations. In flight, where hundreds of lives are now dependent, these metacognitive abilities become increasingly important. Pilots must assess their personal limitations and abilities especially when navigating in and around adverse weather conditions. Beyond selfmonitoring, the pilot must have selfunderstanding about their emotional and physical status. When emotionally charged events occur, pilots must make critical decisions about their ability to deal with flight operations. Understanding one's physical state is equally important because a pilot's physiological status influences flight safety.

When flying, aviators operate their aircraft in a three dimensional space which requires strong Spatial Intelligence. A pilot must be able to judge distance, anticipate closure rates, adjust decent/ascent rates, and stay oriented with the earth. With no visual cues during poor weather conditions, a pilot must be able to visualize or make mental pictures of their navigational track and position.

A strong understanding of the earth's weather patterns and changing environmental conditions are very important in the safe operation of the flight. To navigate safely through adverse conditions, the pilot must understand the nature and developmental characteristics of weather which is considered Naturalistic Intelligence. Aviators need the ability to discriminate and categorize the differences between hazardous weather patterns and safe cloud formations. The pilot must also be able to manipulate his/her aircraft like a precise instrument; therefore, Body-kinesthetic intelligence becomes important. Aircraft, like many machines, make somewhat predictable noises when they are functioning correctly or incorrectly. A pilot's Musical Intelligence can be used to detect subtle noises and harmonic pitch changes which could indicate possible problems in flight. Detecting rotor sound is particularly important for helicopter pilots. A technique used by some pilots to keep the rotor "on speed" is to listen for harmonic pitch changes in the main rotor system. After detecting the 
change in sound, the pilot then utilizes instruments to back up his/her interpretation.

Finally, the pilot must have strengths in the traditional and often most valued academic intelligences, Linguistic and Logical Mathematical intelligence. He/she must have Linguistic Intelligence in order to communicate clearly with ATC and the vast number of people involved in commercial aviation. Furthermore, aviation has its own unique language, which is sometimes difficult to master as a beginning pilot. Flying is a very dynamic process with varying challenges and novel problems. A pilot needs the Logical-mathematical intelligence so he/she can solve problems during critical situations. A pilot's Logical Intelligence can range from solving simple fuel calculations to developing innovative solutions to unforeseen emergencies.

The Aviation Instructor's Handbook is the FAA's primary publication suggesting/recommending ways to instruct and assess student pilots (Federal Aviation Administration, 2008). The FAA's publication provides a good overview of the instructional process including, the learning process, teaching strategies, testing methods, and human behaviors. Many of the theories are cognitivebehavioral which can be attributed to Thorndike's work and Bloom's hierarchical taxonomy (Bloom, Mesia, \& Krathwohl, 1964; Bye \& Henley, 2003). The FAA's instructor handbook also discusses some motivational behaviors and personality theory, with references leaning toward Freud's (1966) Defense Mechanisms, Maslow's (1970) Hierarchy of Needs and Jung's theory of personality (Federal Aviation Administration, 2008).

In an informal polling on the teaching strategies used by undergraduate flight instructors, the authors found that very few if any remembered or employed any teaching methodology suggested by the FAA. In fact, most flight instructors stated that studying for the Fundamentals of Instruction (found in the Aviation Instructor's Handbook) was the most undesirable part of becoming a flight instructor. Most instructors tend to use instructional methods that were taught to them by their instructors or use personal methods which were developed through trial and error. Based on these informal discussions a more applicable instructional and assessment method needs to be explored.

\section{Purpose of the Study}

In order to investigate the applicability of Multiple Intelligence Theory as an enhancement to aviation assessment and education there is a need to explore whether pilots have a Multiple Intelligence (MI) profile different from other professions. To measure an individual's Multiple Intelligence the Multiple Intelligence Developmental Assessment Scale (MIDAS) was used. This measure was chosen because it was specifically designed for educational assessment. If a distinct "pilot profile" is indicated, educational programs could improve teaching strategies by matching course delivery and presentation to the flight student's intelligence profile. If an aviation student does not match the "typical profile," educators could help students improve the less developed intelligences, they could assist the student in developing learning strategies that fit their intelligence profile, or they could utilize an instructional methodology that would match the student's intellectual strengths.

\section{METHOD}

\section{Participants}

Eighty-six adult participants were divided into two groups, Professional Pilots and Flight Students. The professional pilot category included both fixed-wing and rotor-wing aviators. Their professional experience included emergency medical service (EMS), the airlines, corporate aviation, the National Test Pilot Academy, and the military. The professional pilot sample consisted of 31 males. Their mean age was $42.6 \quad(\mathrm{SD}=10.6)$. All described themselves as Caucasian, and one identified as Asian. Their average flight experience was 3154 fight hours. The Flight Student sample included 55 adult flight students enrolled in Kent State University's Aeronautics Program. These students were working on certificates and ratings ranging from Private Pilot through Certified Flight Instructor. The sample contained three Hispanic, 47 Caucasian and four selected not to indicate. There were 47 male and eight female 
students. The mean age was $21.5(\mathrm{SD}=3.4)$ and the average flight hours were 164 .

\section{Instrumentation}

The MIDAS, was used to measure a participant's Multiple Intelligence strengths. The MIDAS provides information regarding intellectual development, activities, and intellectual predispositions (Shearer, 2007). This assessment also provides information based on an individual's experience, which can be used for assessment, personalized learning, and curriculum design. Results from the MIDAS Profile have been used to formulate personalized educational and career plans through the recognition of intellectual strength and potential. The MIDAS produces eight main scale scores, (Gardner's eight intelligences) indicating ones intellectual skill, knowledge, and developed ability as reported by the test taker. The subscales are a qualitative and descriptive understanding of one's skill within a particular intelligence. There are also three intellectual style scales. These scores indicate one's preferred way to solve problems. Scores from the intellectual styles suggest whether one is more inventive (Innovative Scale), practical (General Logic Scale) or social (Leadership Scale) in problem solving. In addition to the MIDAS, participants were asked to complete a data sheet requesting demographic information, including flight hours, pilot certificates, and career aspirations.

\section{Procedures}

This study was descriptive in nature and groups were not randomly assigned. Participants were asked to complete an informed consent form, a basic data sheet, and the MIDAS assessment. A description of the study was in the analysis packet and stated that the information gathered from the research was going to be used for educational improvement and the assessment of pilots. No deception was used in this study. To recruit professional pilots, companies were contacted asking for volunteers. Companies that agreed posted sign-up sheets and provided analysis packets for the pilots. NASA Glenn Research Center was also contacted to recruit volunteers from the National Test Pilot Academy. Test pilots who agreed to participate were given analysis packets in class.
Flight students at Kent State University were asked to participate in the study for extra credit. All participants were asked to complete the questionnaire and assessment at their leisure and return it to the researcher. All completed assessments were collected and imported into SPSS for analysis. The results were compared to other professions (See Table 5).

\section{RESULTS}

The mean frequency was calculated for all the MIDAS main scales and subscales. Both Professional Pilots and Flight Students scored high on Spatial Intelligence and Intrapersonal Intelligence respectively (See Tables 1-4). Professional Pilots mean scores on Spatial Intelligence was $66.07(\mathrm{SD}=11.8)$ and a mean of 65.69 (SD = 11.76) on Intrapersonal Intelligence. Flight Student mean scores on Spatial Intelligence was $63.66(\mathrm{SD}=13.6)$ and a mean score of $63.33(\mathrm{SD}=9.88)$ on Intrapersonal Intelligence. For Professional Pilots and Flight Students the Subscale mean scores were in the high range on Spatial Problem Solving, Spatial Awareness, Personal Knowledge, and Working with Objects respectively.

\section{DISCUSSION}

The results of this investigation report that there seems to be a "pilot profile." Pilots scored high on Spatial Intelligence and Intrapersonal Intelligence. This suggests that pilots "think in pictures and perceive the visual world accurately" (Shearer, 2007, p. 31). Pilots prefer to think in three dimensions and transform perceptions by re-creating one's visual experience via imagination. Pilots also report thinking about and understanding themselves by knowing their strengths and weaknesses, thus helping them plan effectively to achieve a goal. On the subscales, Professional Pilots and Flight Students employ the same four skills used within a particular intelligence. Pilots' indicated self-awareness in solving problems and spatial orientation dilemmas while moving self and objects through space. Pilots have an awareness of their ideas and the abilities to achieve personal goals. Furthermore, pilots report the ability to build, fix, and assemble things. 
These reported intelligences or strengths seem very relevant to success in aviation. A pilot must be able to think and solve spatial problems while flying. There are important goals to achieve during flight making selfawareness an essential factor in the decisionmaking process. Pilots also must understand the mechanical function, interactions, and design of their aircraft. Having these intelligences is equally important for aviation education since pilots train for accuracy in flight and must have a strong understanding of aircraft systems. In theory, if a person is already strong in these intelligences then they may have an easier time with the current educational model used in aviation training.

The MI profile for pilots found in this study replicates other research conducted using the MIDAS (Shearer, 1996). Different professions seem to have their own unique profiles (Shearer, 2007). For example, music teachers tend to score high on Musical Intelligence, Linguistic Intelligence and Intrapersonal Intelligence respectively (see Table 5). They also have similar strengths within each intelligence which are quite different from the strengths indicated by pilots in this investigation.

Flight instructors will encounter different learning styles and differing abilities among their students. At present, it appears that little pre-assessment of a student's intellectual capabilities or learning styles are ever conducted. Most often, students must conform to the instructional techniques and methodologies used by their flight instructors. This learning is not always a simple transfer of knowledge, but involves the students ability to interact with the learning environment (Lintern, 1995). This interaction is done through a flight student's intellectual strengths and learning styles. Educators, including flight instructors, typically teach within their intelligence profile and learning style (Kallenbach \& Viens, 2004). This teaching method (or comfort) does not always match the student's intellectual preference. Therefore, it is just as important for the flight instructor to know his/her own multiple intelligence profile as it is to know that of their students (Green \& Tanner, 2005; Kallenbach \& Viens, 2004). The idea of understanding oneself and his/her student is suggested by the FAA (Federal Aviation Administration, 2008). According to the FAA (2008), "The match or mismatch between the way an instructor teaches and the way a student learns contributes to student satisfaction or dissatisfaction. Students whose learning styles are compatible with the teaching styles of an instructor tend to retain information longer, apply it more effectively, learn more, and have a more positive attitude toward the course in general” (p. 3).

It seems that many flight instructors have limited knowledge of instructional strategies that they could use in various situations. They may also lack actual teaching experience which tends to become increasingly evident as flight instructors get hired by the airlines with minimal flight hours (Henley, 1991). Based on the results of this research, it appears that a possible reason why flight students complete their flight education is that their multiple intelligence profiles (or intellectual strengths) may be closely related to their instructors. The mean scores from the 86 participants in this investigation indicated that a pilot's intelligence strengths are located in the Spatial, Intrapersonal and Logicalmathematical domains (See Tables 1-4). There are also similarities found in the learning styles of pilots (Kanske \& Brewster, 2001). Research further suggests that gender differences relating to personality within the pilot population are less than what exists between males and females found in national norms outside of aviation (King, 1999).

In theory, if pilots have similar intelligence profiles, and are successful because of these intellectual similarities, then it may be that some students not fitting this profile may discontinue flight training due to frustration. A student may feel that he/she does not possess the "Right Stuff." Where, in reality, the learning material may have been presented poorly, the educational system may inadvertently be skewed toward a typical MI pilot profile, or the student may not have an awareness of the learning and study strategies necessary to capitalize on their intellectual strengths to assist them in succeeding in flight training.

From these observations and preliminary findings, the theory of multiple intelligences may be a very functional model to assess and 
educate aviators. Upon further research, it is possible that MI Theory could be included in the FAA's Flight Instructor Handbook. Instructional methodologies could be implemented to fit the "typical" pilot profile or be altered to fit more diverse MI Profiles. Based on the results of this investigation, it appears that MI theory may be more useful than some other psychological assessments because it does not overly rely on complicated terminology. Because of this, individuals new to flight instruction can easily grasp the concepts. Additionally, these concepts can be integrated with instructional and learning strategies to greatly enhance flight instruction and training.

This is the first in a series of investigations focusing on the use of multiple intelligence theory in improving aviation education. Future studies will include determining the instructional and learning strategies appropriate for enhancing learning for each of the intelligences. In addition, studies have recently begun exploring the effects of matching students and instructors with similar Multiple Intelligence profiles. 


\section{REFERENCES}

Anderson, J. R. (1995). Cognitive psychology and its implications. New York W. H. Freeman and Company.

Armstrong, T. (1999). 7 kinds of smart: Identifying and developing your multiple intelligence. Harmondsworth: Plume.

Armstrong, T. (2000). Multiple intelligences in the classroom (2nd ed.). Alexandria: Association for Supervision and Curriculum Development.

Bloom, B. S., Mesia, B. B., \& Krathwohl, D. R. (1964). Taxonomy of educational objectives: The affective domain \& the cognitive domain. New York: David McKay.

Boring, E. G. (1923). Intelligence as the tests test it. New Republic, 35, 35-37.

Bye, J., \& Henley, I. (2003). Learning theories and their application to aviation. In I. Henley (ed.), Aviation Education and Training. Burlington: Ashgate.

Craig, D. V., \& Garcia, G. (2001). Multiple styles, multiple strategies: Employing learning theories for flight instruction. Paper presented at the UAA Fall Education Conference, Nashville.

Davidson, J. E., \& Downing, C. L. (2000). Contemporary models of intelligence. In R. J. Sternberg (ed.), Handbook of intelligence (pp. 34-49). New York: Cambridge University Press.

Federal Aviation Administration. (2008). Aviation instructors handbook. Washington, DC: U.S. Department of Transportation.

Gardner, H. (1983). Frames of the mind: The theory of multiple intelligence. New York: Basic Books.

Gardner, H. (1993). Multiple intelligence: The theory in practice. New York: Basic Books.

Gardner, H. (1999). Intelligence reframed. New York: Basic Books.

Gardner, H. (2006). On failing to grasp the core of MI theory: A response to visser et al. Intelligence, 34, 503-505.

Gardner, H., \& Moran, S. (2006). The Science of Multiple Intelligences Theory: A Response to Lynn Waterhouse. Educational Psychologist, 41(4), 227-232.

Green, C., \& Tanner, R. (2005). Multiple intelligences and online teacher education. ELT Journal, 59(4), 312-321.

Gregory, R. J. (2004). Psychological testing: history, principles, and applications (4th Ed.). Boston: Allyn and Bacon.

Henley, I. (1991). The Development and Evaluation of Flight Instructors: A Descriptive Survey. International Journal of Aviation Psychology, 1(4), 319-333.

Kallenbach, S., \& Viens, J. (2004). Open to Interpretation: Multiple Intelligences Theory in Adult Literacy Education. Teachers College Record, 106(1), 58-66.

Kanske, C. A., \& Brewster, T. (2001). Learning styles of college aviation students Collegiate Aviation Review, 19(1), 62-70.

Kaufam, A. S., \& Lichtenberger, E. O. (1999). Essentials of WAIS-III assessment. New York: John Wiley \& Sons.

King, R. E. (1999). Aerospace clinical psychology. Brookfield: Ashgate.

Lazear, D. (1991). Seven ways of teaching: The artistry of teaching with multiple intelligences. Palatine: IRI/Skylight. 
Lintern, G. (1995). Flight instruction: The challenge from situated cognition. The International Journal of Aviation Psychology, 5(4), 327-350.

Overchuk, E. J. (2008a). Aeronautical decision making and the function of multiple intelligence in pilots. Paper presented at the Midwest Decision Sciences Institute 2008 Conference Erie Pennsylvania.

Overchuk, E. J. (2008b). Developing self defense training for pilots based on their multiple intelligences. Research Abstract presented at the University Aviation Association Conference, Denver Colorado.

Overchuk, E. J. (2008c). Investigating multiple intelligence theory in pilot education and assessment. Research Abstract presented at the University Teaching Council Conference Kent State Ohio.

Overchuk, E. J. (2009). Self defense 101: An exploration of self defense training and its applicability for college flight majors. The Journal of Aviation/Aerospace Education \& Research, 18(3), 9-18.

Shearer, B. (1996). The MIDAS: a professional manual. Kent: MI Research \& Consulting.

Shearer, B. (2004a). Multiple intelligences theory after 20 years. Teachers College Record, 106(1), 2-16.

Shearer, B. (2004b). Using a Multiple Intelligences Assessment to Promote Teacher Development and Student Achievement. Teachers College Record, 106(1), 147-162.

Shearer, B. (2007). The MIDAS: a professional manual: Revised. Kent: MI Research \& Consulting.

The Psychological Corporation. (1997). Wechsler adult intelligence scale (3rd Ed.). Boston: The Psychological Corporation.

Wissler, C. (1901). The correlation of mental and physical tests. The Psychological Review, Monograph Supplement, 3(6).

Wolman, B. B. (1985). Handbook of intelligence: theories, measurements, and applications. New York: Wiley. 


\section{APPENDIX}

Table 1. Flight Student Main Scale Descriptive Statistics

\begin{tabular}{lcc}
\hline Intelligence Scales & Mean & Standard Deviation \\
\hline Spatial & 63.66 & 13.63 \\
Intrapersonal & 63.33 & 9.88 \\
Interpersonal & 59.71 & 12.29 \\
Kinesthetic & 57.65 & 12.86 \\
Logical & 56.82 & 14.34 \\
Naturalist & 54.32 & 15.48 \\
Linguist & 51.58 & 14.61 \\
Musical & 45.06 & 17.54 \\
\hline
\end{tabular}

$\mathrm{N}=55$

Table 2. Professional Pilot Main Scale Descriptive Statistics

\begin{tabular}{lcc}
\hline Intelligence Scales & Mean & Standard Deviation \\
\hline Spatial & 66.07 & 11.80 \\
Intrapersonal & 65.69 & 11.77 \\
Logical & 61.93 & 13.59 \\
Naturalist & 52.05 & 12.85 \\
Interpersonal & 51.04 & 17.68 \\
Linguist & 50.15 & 14.79 \\
Kinesthetic & 45.71 & 11.67 \\
Musical & 38.57 & 20.79 \\
\hline
\end{tabular}

$\mathrm{N}=31$

MIDAS Scale Score Categories for all Tables:

$100-80=$ Very High

$79-60=$ High

$59-40=$ Moderate

$39-20=$ Low

$19-0=$ Very Low 
Table 3. Flight Student Descriptive Statistics of Subscales

\begin{tabular}{lcc}
\hline \multicolumn{1}{c}{ Intelligence Subscales } & Mean & Standard Deviation \\
\hline Spatial Problem Solving & 72.55 & 16.18 \\
Spatial Awareness & 72.09 & 16.35 \\
Personal Knowledge & 68.12 & 14.17 \\
Working with Objects & 67.61 & 15.55 \\
Problem Solving & 64.55 & 19.39 \\
Social Persuasion & 64.24 & 16.95 \\
General Logic & 63.93 & 10.97 \\
School Math & 61.36 & 26.47 \\
\hline $\mathrm{N}=55$ & &
\end{tabular}

Table 4. Professional Pilots Descriptive Statistics of Subscales

\begin{tabular}{lcc}
\hline \multicolumn{1}{c}{ Intelligence Subscales } & Mean & Standard Deviation \\
\hline Spatial Problem Solving & 79.84 & 13.51 \\
Spatial Awareness & 79.03 & 14.91 \\
Personal Knowledge & 69.25 & 12.97 \\
Working with Objects & 67.56 & 13.06 \\
School Math & 65.19 & 28.02 \\
Problem Solving & 64.91 & 18.50 \\
General Logic & 63.75 & 12.48 \\
Social Persuasion & 60.35 & 20.88 \\
\hline $\mathrm{N}=31$ & &
\end{tabular}


Table 5. Comparison of Different Professions on Main scale and Subscale MIDAS Scores (Shearer, 2007)

\begin{tabular}{|c|c|c|c|c|c|c|c|c|}
\hline & Pilots & $\%$ & Engineers & $\%$ & Lawyers & $\%$ & $\begin{array}{l}\text { Business } \\
\text { Consultants }\end{array}$ & $\%$ \\
\hline \multirow[t]{3}{*}{ Main scales } & Spatial & 67 & Math-Logic & 64 & Linguistic & 69 & Interpersonal & 70 \\
\hline & Intrapersonal & 66 & Intrapersonal & 63 & Intrapersonal & 61 & Intrapersonal & 69 \\
\hline & Math-logic & 62 & Spatial & 61 & Interpersonal & 60 & Math-logic & 60 \\
\hline \multirow[t]{6}{*}{ Subscales } & $\begin{array}{l}\text { Spatial Problem } \\
\text { Solving }\end{array}$ & 81 & School Math & 80 & $\begin{array}{l}\text { Writing/ } \\
\text { Reading }\end{array}$ & 81 & $\begin{array}{l}\text { Personal } \\
\text { Knowledge }\end{array}$ & 79 \\
\hline & $\begin{array}{l}\text { Spatial } \\
\text { Awareness }\end{array}$ & 80 & $\begin{array}{l}\text { Spatial Problem } \\
\text { Solving }\end{array}$ & 71 & Persuasion & 70 & Persuasion & 77 \\
\hline & $\begin{array}{l}\text { Personal } \\
\text { Knowledge }\end{array}$ & 69 & Calculations & 69 & Rhetorical & 68 & Management & 75 \\
\hline & Science & 68 & $\begin{array}{l}\text { Spatial } \\
\text { Awareness }\end{array}$ & 67 & $\begin{array}{l}\text { Personal } \\
\text { Knowledge }\end{array}$ & 68 & $\begin{array}{l}\text { Work with } \\
\text { People }\end{array}$ & 73 \\
\hline & $\begin{array}{l}\text { Work with } \\
\text { Objects }\end{array}$ & NA & $\begin{array}{l}\text { Personal } \\
\text { Knowledge }\end{array}$ & 63 & Self Effective & 67 & Self Effective & 70 \\
\hline & Phys. Assts. & $\%$ & Naturalists & $\%$ & $\begin{array}{l}\text { Educators, } \\
\text { PhD }\end{array}$ & $\%$ & $\begin{array}{l}\text { Music } \\
\text { Teachers }\end{array}$ & $\%$ \\
\hline \multirow[t]{3}{*}{ Main scales } & Linguistic & 71 & Naturalist & 71 & Interpersonal & 72 & Musical & 74 \\
\hline & Interpersonal & 69 & Intrapersonal & 61 & Linguistic & 71 & Linguistic & 69 \\
\hline & Intrapersonal & 65 & Math-logic & 58 & Intrapersonal & 66 & Intrapersonal & 59 \\
\hline \multirow[t]{5}{*}{ Subscales } & $\begin{array}{l}\text { Writing/ } \\
\text { Reading }\end{array}$ & 83 & $\begin{array}{l}\text { Writing/ } \\
\text { Reading }\end{array}$ & 79 & Management & 83 & Instrumental & 86 \\
\hline & Management & 75 & Science & 70 & $\begin{array}{l}\text { Writing/ } \\
\text { Reading }\end{array}$ & 82 & $\begin{array}{l}\text { Writing/ } \\
\text { Reading }\end{array}$ & 79 \\
\hline & $\begin{array}{l}\text { Work with } \\
\text { People }\end{array}$ & 74 & $\begin{array}{l}\text { Personal } \\
\text { Knowledge }\end{array}$ & 65 & Persuasion & 81 & Composing & 77 \\
\hline & $\begin{array}{l}\text { Spatial Problem } \\
\text { Solving }\end{array}$ & 84 & $\begin{array}{l}\text { Spatial Problem } \\
\text { Solving }\end{array}$ & 63 & $\begin{array}{l}\text { Work with } \\
\text { People }\end{array}$ & 79 & $\begin{array}{l}\text { Music } \\
\text { Appreciation }\end{array}$ & 74 \\
\hline & Social Awareness & 73 & $\begin{array}{l}\text { Spatial } \\
\text { Awareness }\end{array}$ & 63 & $\begin{array}{l}\text { Personal } \\
\text { Knowledge }\end{array}$ & 78 & $\begin{array}{l}\text { Expressive } \\
\text { Sense }\end{array}$ & 70 \\
\hline
\end{tabular}

